\title{
Determining Attributes of Spatial Organization in Public Open Space
}

\author{
Adiba Shafique* and Roshida Abdul Majid \\ Faculty of Built Environment, Universiti Teknologi Malaysia, Johor Bahru, Malaysia
}

\begin{abstract}
Spatial organization can be attributed to diverse physical factors in Public open space. The spatial organization act as one of the major factors for describing the identity of the architecture of a particular space and builds a relationship between architecture spaces with culture and their application. Therefore, this research explores the factors of spatial organization for making effectual public open space in Indian context. The research has been unfolded into two steps. Firstly, literature review has been done followed by questionnaire survey. Three different Public open spaces of New Delhi, India including New Friends colony, Saket, Nehru Place has been taken as site study over which questionnaire survey has been performed. The questionnaire design is based on the 'Likert scale' ranging from 1 to 5 i.e. from 'strongly disagree' to 'strongly agree'. Each factor is divided into different construct having five to seven items which is analysed through Cronbach's alpha in order to evaluate the authenticity of response by users. Further, exploratory factor analysis using IBM SPSS software has been employed to explore the factors of spatial organization in Indian Public open space. The factors are further confirmed through confirmatory factor analysis using Amos software. Furthermore, the research findings confirm accessibility and linkages, uses and activities, facilities and microclimate are the major factors of spatial organization of public open spaces in Indian context.
\end{abstract}

Keywords: Spatial Organisation, Public Open Space, Indian context

\section{Introduction}

The public open space is certainly a predominant component of public life. Lofland (1998) explained term public spaces as an area which covers a diverse connection between people and space. (Garau, 2016) stressed that design and organization of spaces of public open space explicates the function of the space, building or a city. Therefore, while designing Public open space, spatial organization and design should be in perpetuation of the context of a city and mutate according to the users need. However, Zakariya et al. (2016), identifies, spatial organization as one of the predominant factor of Public open space, to enhance the social interaction. The aim of the research paper is to determine the factors of spatial organization of a Public open space successful in Indian context. The results of the study will provide comprehensive understanding in context of spatial organization in Public open space which eventually further helps in making effective Public open space. The objective of the study will be achieved by conducting case study in three different Public open space of New Delhi India.

\section{Literature Review}

\section{Spatial Organisation}

Goffman (1963) reported the spatial organisation has a major impact people's behaviour and their level of interaction in public open space. Zakariya et al. (2016) asserted that spatial organisation and elements in Public open space is highly linked to social interaction as desired spatial organisation, attracts people for a longer duration which further helps in enhancing the productiveness of public open space. Zakariya et al. (2016) further mentioned that, organisation of spaces produces association between spaces as well as provide possibilities for sociability. 


\begin{tabular}{|c|c|c|}
\hline $\begin{array}{l}\text { Factors of Spatial organization } \\
\text { for social sustainability (Thwaites } \\
2005 \text { ) }\end{array}$ & $\begin{array}{l}\text { Factors of Spatial } \\
\text { organization (Parsaee, } \\
\text { Parva et al. 2015) }\end{array}$ & $\begin{array}{l}\text { Factors of public open } \\
\text { spaces }\end{array}$ \\
\hline \multicolumn{3}{|l|}{ Directional space } \\
\hline Deflective facades & & Linkage \\
\hline Façade continuity & & Access \\
\hline Rhythm of boundary treatment & & $\begin{array}{l}\text { Urban elements/ } \\
\text { Amenities (Facilities) }\end{array}$ \\
\hline Linearity of floorscape & & Access \\
\hline Views and focal points & & Linkage \\
\hline \multicolumn{3}{|l|}{ Transitional space } \\
\hline $\begin{array}{l}\text { Thresholds:boundaries between } \\
\text { spaces marked by change in: } \\
\text { material, texture, color, form/shape, } \\
\text { direction, level }\end{array}$ & $\begin{array}{l}\text { Type of spatial } \\
\text { organization }\end{array}$ & $\begin{array}{l}\text { Urban elements/ } \\
\text { Amenities (Facilities) }\end{array}$ \\
\hline $\begin{array}{l}\text { Segments: spaces that break } \\
\text { linearity and provide 'softness' } \\
\text { through: porticos, arcades, } \\
\text { colonnades, shelters, low fencing, } \\
\text { stoops, porches and landings etc. }\end{array}$ & $\begin{array}{l}\text { Type of circulation } \\
\text { system }\end{array}$ & Access \& Mobility \\
\hline $\begin{array}{l}\text { Corridors and Tunnels: narrow } \\
\text { routes between buildings enabling } \\
\text { access to interior courtyards or } \\
\text { through routes to neighboring } \\
\text { spaces. }\end{array}$ & $\begin{array}{l}\text { Type of circulation } \\
\text { system }\end{array}$ & Access \\
\hline $\begin{array}{l}\text { Ephemeral: transient effects of sun } \\
\text { and shade patterns, seasonal change } \\
\text { in vegetation, sounds, smells etc. }\end{array}$ & & Microclimate \\
\hline \multicolumn{3}{|l|}{ Locational space } \\
\hline Separation from Distraction & Private and public zones & $\begin{array}{l}\text { Urban elements/ } \\
\text { Amenities (Facilities) }\end{array}$ \\
\hline Provision of Access & & Access \\
\hline Provision for Comfort & & Comfort \\
\hline $\begin{array}{l}\text { Opportunities for Interaction with } \\
\text { the Environment }\end{array}$ & & $\begin{array}{l}\text { Urban elements/ } \\
\text { Amenities/uses and } \\
\text { activities }\end{array}$ \\
\hline Place attachment & & Place attachment \\
\hline Features of interest & functional areas & $\begin{array}{l}\text { Urban elements/ } \\
\text { Amenities (Facilities) }\end{array}$ \\
\hline Opportunities for social interaction & & uses and activities \\
\hline
\end{tabular}

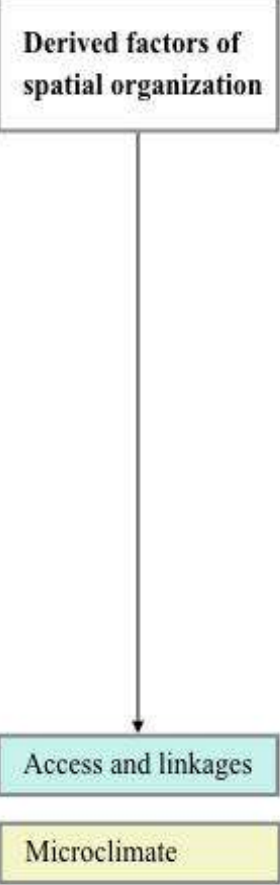

Uses and Activities

Facilities

Figure 1 showing attributes of spatial organization of public open space derived from literature review 


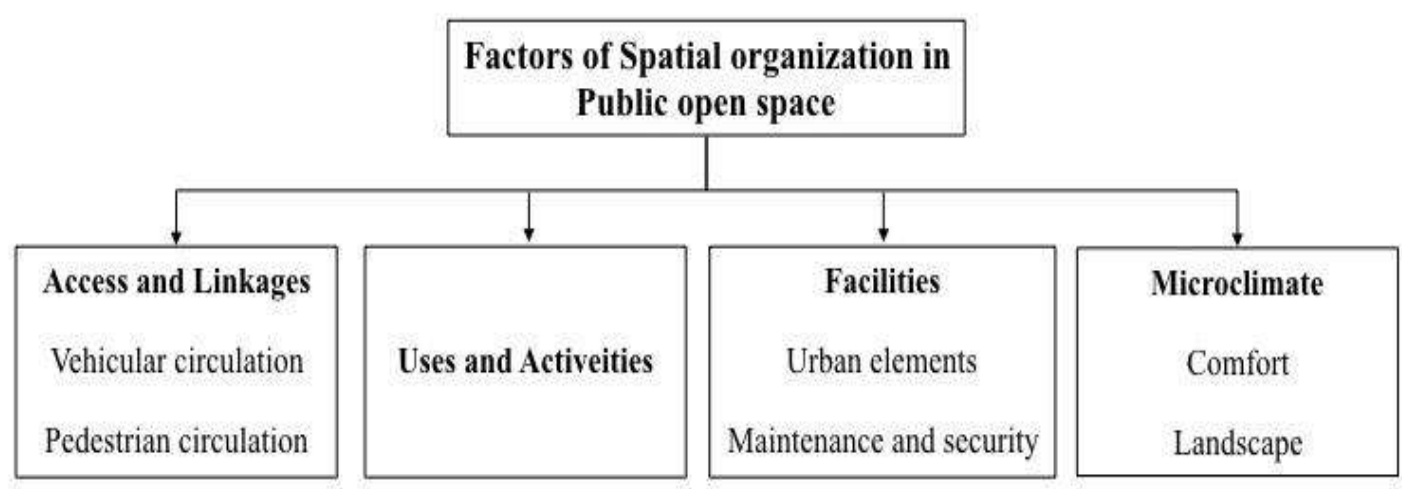

Figure 2 Derived factors of spatial organization in Public open space

Nezhad et al. (2003) elucidates that spatial organisation involves the design and layout of spaces, as to accomplish few consideration which construct the rate and type of relation between elements. Further, Nezhad et al. (2003) added that the order, sequence and position of spaces administrates the organisation. Moreover, every organisation has a distinct influence on semantic relationships between spaces. Each place needs different semantic relationship and spatial organisation as they possess different cultures and context. According to Melik (2008), to attain successful public open space, spatial organisation and design of space should be in a relation of social life of place. While, Whyte (1980), identified flexible design, public amenities, signages, circulation, shades, sit outs as major components of spatial organisation as it has immense impact on social life and encourages in generating effective public open space.

Furthermore, Torabi and Brahman (2013) linked architecture spaces with the culture of a place, moreover, defines spatial organisation as essential attribute for illustrating the identity of the architecture of a particular space. Whilst, Fichter (2013) comments that every person or a group have a contrasting outlook on exploring a public space. A spatial organisation of Public open space should be such that a person should be able to develop sense of belonging.

\section{Factors of Spatial Organisation in Public open space}

Thwaites (2005) described different types of spaces and some features of spatial organization towards social sustainability in public open spaces. Therefore, in this study factors of spatial organization have been extracted from the determinants of public open space on the basis of literature review (figure 1). The extracted parameters are Access and linkages, uses and activities, facilities and microclimate.

\section{Accessibility and linkages}

Whyte (1980) describe, access as a visible reach of the space, while Tibbalds (1992) mentioned accessibility as a physical and visual approach of a space which have an immense impact on the user's perception. Tabassum and Sharmin (2013) states that open spaces with better accessibility encourages social cohesion and interaction. While, Taghipour et al. (2015) defined linkages as a connection between spaces, inner and outer circulation.

\section{Uses and activities}

Taghipour et al. (2015) described uses and activities as one of the essential factors to rejuvenate the Public open space in different time and season. According to Gehl (1996), in public space, people are attracted by people and 
activities gets attracted by activities. Therefore, it is important to put uses and activities as it generates social interaction and captivates public for longer duration.

\section{Facilities}

Facilities include urban elements and maintenance and security. Carmona (2008) stated that the quality and organization of urban elements is directly related to the quality of public space. While, Whyte (1980) considered, installation of small visually pleasing urban elements like sit outs, installations, cascades attract users. Carmona (2008) mentioned that at different time of a day i.e. day and night, users perceive place differently. Therefore, public space should have the security provision of both day and night. Rimanova (2010) safety and maintain are the two essential factors for the success of Public open space.

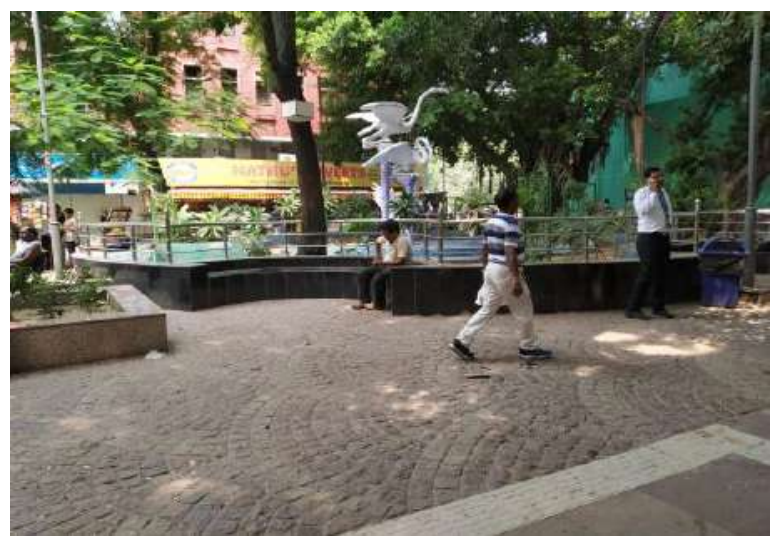

Figure 3 Public open space, New Friends colony, New Delhi

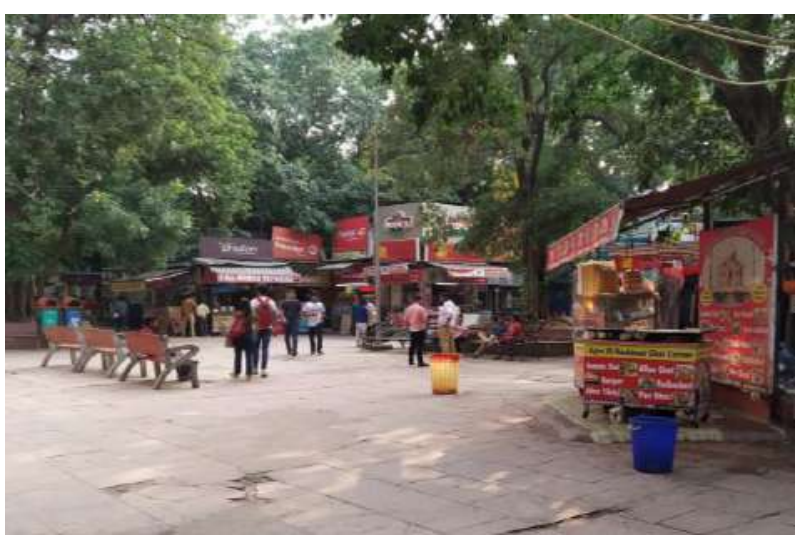

Figure 4 Public open space, Saket, New Delhi

\section{Microclimate}

Gehl (1996); Mehta (2014) describes microclimate as a climate at micro level, comprises temperature, sunlight, shade and shadow, wind, humidity and a sense of comfort which compliments outdoor activities in Public open space. Thus, this factor is further divided into two parameters including comfort and landscape. Stephen et al. (1992) defines comfort is one of the necessary components of Public open space as it has strong impact on people's satisfaction. While Gehl (1996) asserts that, Comfort and user's activities in Public open space are in relation to each other. Therefore, it is essential to create comfortable environment for users. Further, Kaplan and Kaplan (1989) also describe physiological comfort as one of the perquisites for generating social interaction in Public open space. While, landscape includes components like sitting area, water bodies, fountain, cascade, green areas, encourages users to stay for longer duration. According to Spooner (2014) social interaction in Public open space is highly depend on the physical quality. Moreover, landscape is one of an attribute of a physical quality which compliments the social connects between an individual or a group (Spooner, 2014).

\section{Methods}

\section{Description of Study Area}

The study adopted three different Public open space of New Delhi, so that the context and the size of the site should be different, while character of the city does not change. Adding to this, design spaces are different of each Public open space, in order to get contrasting responses from the users. Thus, according to specified 
parameters, Public open space of Saket, Nehru Place and New Friends Colony are considered for the case study. These Public open spaces are the part of District centre which includes varied land uses like commercial areas, offices, Hotels, restaurants, etc. Therefore, the selected site caters to different users.

\section{Data Collection}

For data collection, research has adopted quantitative method. A set of questionnaires is designed to find out the factors of spatial organization in Indian context. Thus, 26 questions were framed, which inquiries about users satisfaction level regarding present factors of spatial organization in Public open space. The questionnaire is based on the Likert scale ranging from 1 to 5 "highly disagree to highly agree," containing four different factors with 26 items. Prior to survey, pilot study with 19 samples has been done in order to validate the questionnaire. The results of data collection specify the satisfaction level of users in terms of spatial organization of Public open space in selected study area.

\section{Sample size}

Table 1 showing exploratory factor analysis of attributes of spatial organization of public open space

\begin{tabular}{|c|c|c|c|c|}
\hline Construct & $\begin{array}{l}\text { No. } \\
\text { of } \\
\text { items }\end{array}$ & Indicators & $\begin{array}{l}\text { Factor } \\
\text { loading }\end{array}$ & $\begin{array}{l}\text { Cronbach' } \\
\text { s Alpha }\end{array}$ \\
\hline \multirow{6}{*}{$\begin{array}{l}\text { Access and } \\
\text { linkages }\end{array}$} & \multirow[t]{6}{*}{6} & Entrance is good & 0.778 & \multirow[t]{6}{*}{0.940} \\
\hline & & Clear entry and exit & 0.775 & \\
\hline & & Easy to get parking space & 0.737 & \\
\hline & & Pedestrian entrance is good & 0.749 & \\
\hline & & Walkable distance from bus, metro to public open space & 0.787 & \\
\hline & & Size and condition of walkways are good & 0.798 & \\
\hline \multirow{5}{*}{$\begin{array}{l}\text { Uses and } \\
\text { activities }\end{array}$} & \multirow[t]{5}{*}{5} & Spaces are attractive & 0.776 & \multirow[t]{5}{*}{0.928} \\
\hline & & Activities are sufficient to spend time & 0.787 & \\
\hline & & Diversity in activities & 0.781 & \\
\hline & & Activities for less abled, senior citizens & 0.767 & \\
\hline & & Sufficient area for shopping, relaxing & 0.785 & \\
\hline \multirow[t]{6}{*}{ Facilities } & \multirow[t]{6}{*}{6} & Diversitylin physical form & 0.755 & \multirow[t]{6}{*}{0.937} \\
\hline & & Spaces with proper sit-outs & 0.788 & \\
\hline & & Toilets, drink water and first aid available & 0.781 & \\
\hline & & Street furniture and street lightings are available & 0.788 & \\
\hline & & Night lighting and security camera are properly installed & 0.788 & \\
\hline & & Spaces are clean and well maintained & 0.744 & \\
\hline \multirow[t]{5}{*}{ Microclimate } & \multirow[t]{5}{*}{8} & Shade protect the play areas from climatic condition & 0.798 & \multirow[t]{5}{*}{0.958} \\
\hline & & Sitting with proper shades (temporary/trees) & 0.800 & \\
\hline & & Well maintained and shaded pathways & 0.788 & \\
\hline & & No noise/smell in surrounding & 0.818 & \\
\hline & & Open space layout design \& elements are captivating & 0.780 & \\
\hline
\end{tabular}


Water fountain/Statues/sculpture are attractive

The Delhi City has a finite population of 2,733,752 (2011 census). Israel (1992) sample formula for finite population has been used as for sample size calculation. Thus, according to the Israel (1992), 400 samples for the population more than 100,000 , assuming _+ $5 \%$ precision level has been taken.

Thus, the sample size is 461 which is collected from three different Public open space of New Delhi i. e., from each site around 154 samples are collected. Moreover, systematic sampling is used in which, every fourth visitor is counted and requested to answer the question. Through observation, spots are finalised. Further, in order to construct reliable samples, time-interval technique is used by conducting survey in first 10 minutes of every hours.

The combination of these two techniques are used by (Akari, 2014) to assess the public open space as well as (Ja'afar and Bina, 2009) supported for these techniques for the similar research. The samples collected are almost equal in terms of gender and age as to avoid imbalance in reviews from one gender.

\section{Data Analysis}

The data analysis has been performed in three different stages. In first stage, Cronbach's alpha value of each factor has been checked for ensuring the reliability of data. Prior to this, data screening has been done, which includes finding missing values, checking outliers and normality using IBM SPSS. As recommended by Cronbach (1951), alpha value above 0.7 is consider as reliable. Through table 1, it can be assessed that all the items are above the required 0.7 value of Cronbach's alpha. In stage two, Exploratory factor analysis using Varimax rotation on IBM SPSS has been performed to validate the items of each construct through factor loading of each item. According to Hurley et al.(1997), items having factor loading less than 0.5 are identified and and deleted from the construct. Thus, out of 28 items, 2 items are identified and removed from the construct as it showing less than 0.5 factor loading value. At last, to examine the successful factors of spatial organization in Public open space, confirmatory factor analysis has been performed on IBM Amos in order to find out the correlation between each factor as well as factor loading of each item and construct 


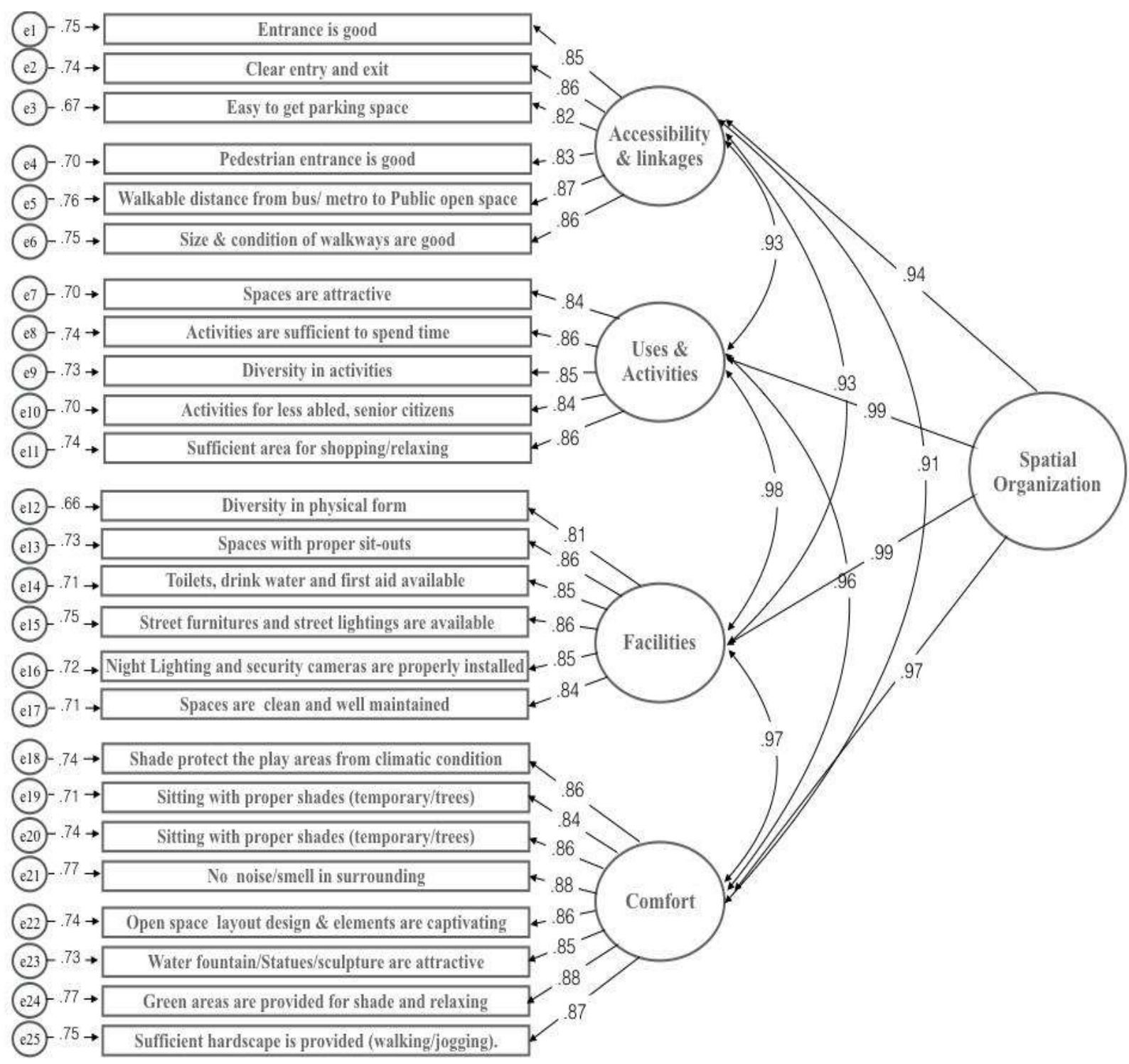

Figure 5 showing results of confirmatory factor analysis of spatial organization attributes 


\section{Confirmatory factor analysis}

Table 2 Model fitness indices of spatial organization of public open space

\begin{tabular}{lllllllll}
\hline $\begin{array}{l}\text { Goodness of fit } \\
\text { measures }\end{array}$ & $\begin{array}{l}\text { X2 test } \\
\text { statistics/df }\end{array}$ & GFI & CFI & NFI & AGFI & RMSEA & RMR \\
\hline $\begin{array}{l}\text { Recommended } \\
\text { value }\end{array}$ & $\leq 3.00 \mathrm{a}$ & $\geq 0.90 \mathrm{~b}$ & $\geq 0.90 \mathrm{~b}$ & $\geq 0.90 \mathrm{~b}$ & $\geq 0.90 \mathrm{~b}$ & $\leq 0.08 \mathrm{c}$ & $\leq 0.1 \mathrm{c}$ \\
\hline Structural model & 1.363 & 0.939 & 0.992 & 0.971 & 0.926 & 0.028 & 0.021 \\
\end{tabular}

Note: $\mathrm{N}=461 ;$ GFI = Goodness-of-Fit Index; AGFI = Adjusted Goodness-of-Fit Index; CFI = Comparative Fit Index; NFI $=$ Normed Fit Index; RMSEA $=$ Root Mean Square Error of Approximation; RMR $=$ Root Mean Square Residual Source: a (Jöreskog and Sörbom 1986), b (Bagozzi and Yi 1988), b (Anderson and Gerbing 1988), c (Browne and Cudeck 1993)

Holtzman and Vezzu (2011), confirmatory factor analysis is a part of structural equation modelling which investigates the relationship between latent variable of a design model and confirms model fitness concerning data. According to Child (1990) Bryne (2016), confirmatory factor analysis inquires the relationship between latent, observed, unobserved variables and constructs. While Holtzman and Vezzu (2011) added that, confirmatory factor analysis comprises exogenous (independent) and endogenous (dependent) variable with indirect and direct effects of one variable on other.

\section{Validity and Reliability}

The validity and reliability of a model can be check through the model fitness. There are few indices which testify the goodness of fit of a model. This includes CMIN (likelihood ratio of chi square), GFI (goodness of fit index), CFI (comparative fit index), NFI (Normed Fit Index), AGFI (Adjusted Goodness-of-Fit Index), RMSEA (Root Mean Square Error of Approximation), RMR (Root Mean Square Residual).

According to Joreskog and Sorbom (1986), the value of CMIN should be less than 5, while Bagozzi and Yi (1988); Anderson and Gerbing (1988) recommended values of GFI, CFI, NFI, AGFI $\geq 0.90$. Further, Browne and Cudeck (1992) commend values of RMSEA $\leq 0.08$ and RMR $\leq 0.1$. (Rasidi et al., 2012) explained that the CFI and NFI explains descriptive fitness and demonstrate the part of development of overall fit model depend on independent model, while CFI is independent from sample size. Further, Rasidi et al. (2012) mentioned that RMSEA depends on degree of freedom as well as indicates the badness of fit index

\section{Main Results}

Before performing exploratory factor analysis, outliers are identified and deleted from the dataset. Bollen-Stine bootstrap has been carried out for multivariate normality, showing significant result ( $p$ value $=0.257$ bootstrap), 
which is above the required value of 0.05 . Thus, this demonstrate that the dataset is normally distributed (Byrne, 2016).

The collected data consist total 461 respondents including 219 female (49.6\%) and 224 males (50.6\%). While, the age groups are unevenly distributed following 0-18 (15.8\%), 18-30 (44.2\%), 31-50 (29.1\%) and 50 above $(10.8 \%)$. The majority of the visitors from age group 18-30 years. While, it has been tried to get equal number of samples from each group.

Moreover, table 1 demonstrating, exploratory factor analysis results demonstrates that values of each item are significantly positive results, which is about 0.7 value as recommended by (Hurley et al., 1997). The factor loading of accessibility and linkage is are $0.778,0.775,0.737,0.749,0.787$ and 0.798 , while uses and activities have $0.776,0.787,0.781,0.767$ and 0.785 . On the other hand, Facilities factor loading includes $0.755,0.788$, $0.781,0.788,0.788$ and 0.774 , whereas,

Microclimate factor loadings are $0.798,0.800,0.788,0.818,0.780,0.803,0.801,0.805$.

Furthermore, results of confirmatory factor analysis shown in figure 1, that all the factors have significantly high correlation with each other which proves that all the assumed factors of spatial organization are fit in Indian context. The relation of accessibility and linkages with uses and activities is 0.93 , with facilities is 0.93 and with microclimate is 0.91 . Further, uses and activities with facilities is 0.98 , with microclimate is 0.96 . Furthermore, facilities with microclimate is 0.97 .

\section{Validity and Reliability of factors of spatial organization model}

The measurement model of spatial organisation shown in table 2, produced the goodness-of-fit indices which are as follows: chi-square value ( $\mathrm{x} 2$ /df $)$ of $1.363, \mathrm{GFI}=0.939, \mathrm{AGFI}=0.926, \mathrm{SRMR}=0.021, \mathrm{NFI}=0.943$, $\mathrm{CFI}=0.992$ and RMSEA $=0.028$. The goodness-of-fit indices showing significant results including GFI, NFI and CFI, which is more than 0.9 (Jöreskog and Sörbom, 1986, Schreiber et al., 2006, Lei and Wu, 2007). This signifies that collected data set is good fit. Therefore, the result reveal that all the mentioned determinants of spatial organization of Public open space are highly essential in Indian context.

\section{Conclusion}

This study has distinctly tried to define the attributes of spatial organization of Indian Public open space. The results of the study comprehensively explain the outputs acquired from the survey dataset. The outputs explain that uses and activities and facilities are the two main factors which mainly defines the spatial organization with a factor Loading of 0.99 as well as showing high correlation also. While, microclimate should be kept as one of the essential factors followed by the accessibility and linkages. Thus, it can be defined as uses and activities, facilities, microclimate and accessibility and linkages are the most significant attributes of spatial organization in Indian Public open space.

\section{References}

AKARI, A. H. 2014. Assessment of urban public spaces; cases of Kuala Lumpur city centre. phd, University of malaya.

ANDERSON, J. C. \& GERBING, D. W. 1988. Structural Equation Modeling in Practice: A Review and Recommended Two-Step Approach. Psychological Bulletin, 103, 411-423.

BAGOZZI, R. P. \& YI, Y. 1988. On the evaluation of structural equation models. Journal of the Academy of Marketing Science, 16, 74-94.

BROWNE, M. W. \& CUDECK, R. 1992. Alternative Ways of Assessing Model Fit. Sage Publications, 21, 230 258. 
BYRNE, B. M. 2016. Structural Equation Modeling With AMOS: Basic Concepts, Applications, and Programming, Nw York / East Sussex, Routledge/Taylor \& Francis.

CHILD, D. 1990. The essentials of factor analysis, London, Cassel Educational Limited.

CRONBACH, L. 1951. Coefficient Alpha and the Internal Structure of Tests. Psychometrika, 297-334.

FICHTER, G. 2013. A cultural footprint in Auckland's Public Space. Master of International Communication, Unitec.

GARAU, P. 2016. Measuring the Magic of Public Space. Le Piazze di Roma. The Journal of Public Space, 1, 17-24.

GEHL, J. 1996. Life Between Buildings: Using Public Space, Copenhagen, Danish Architectural Press and the Royal Danish Academy of Fine Arts, School of Architecture.

GOFFMAN, E. 1963. Behavior in Public Place, New York, The free press.

HOLTZMAN, S. \& VEZZU, S. 2011. Confirmatory Factor Analysis and Structural Equation Modeling of Noncognitive Assessments using PROC CALIS. Statistics and Analysis. New Jersey, USA.

HURLEY, A. E., SCANDURA, T., SCHRIESHEIM, C., BRANNICK, M. T., SEERS, A., VANDENBERG, R. J. \& WILLIAMS, L. J. 1997. Exploratory and confirmatory factor analysis: Guidelines, issues and alternatives. Journal of Organizational Behavior, 18, 667-683.

ISRAEL, G. D. 1992. Determining Sample Size.

JA'AFAR, N. H. \& BINA, J. S. 2009. Physical and Transportation Elements of Traditional Street in Malaysia. European Journal of Social Sciences, 9, 669-676.

JÖRESKOG, K. G. \& SÖRBOM, D. 1986. LISREL VI: Analysis of linear structural relationships by maximum likelihood and least square methods, Mooresville, Ind, Scientific Software.

KAPLAN, R. \& KAPLAN, S. 1989. The Experience of Nature: A Psychological Perspective, Cambridge., Cambridge University Press.

LEI, P. W. \& WU, Q. 2007. Introduction to Structural Equation Modeling : Issues and Practical Considerations. Educational Measurement Issues and Practice, 26, 33-43.

LOFLAND, L. H. 1998. The Public Realm: Exploring the City's Quintessential Social Territory, New York, Aldine de Gruyte.

MATTHEW CARMONA, HAMMOND, L. \& MAGAlHÃES, C. D. 2008. Public space : the management dimension / Matthew Carmona, Claudio de Magalhães, Leo Hammond, London, Routledge.

MEHTA, V. 2014. Evaluating Public Space. Journal of Urban Design, 1, 53-88.

MELIK, R. V. 2008. Changing public space: The recent redevelopment of Dutch city squares. Utrecht University.

NEZHAD, M., KHABARI, M. A. \& MOGHADAM, R. A. 2003. Renovation and Iranian contemporary architecture in the years after the Islamic Revolution. Journal of Iranian -Islamic City.

RASIDI, M. H., JAMIRSAH, N. \& SAID, I. 2012. Urban Green Space Design Affects Urban Residents' Social Interaction. ASIA Pacific International Conference on Environment-Behaviour Studies. Giza, Egypt: Elsevier.

ŘÍMANOVA, M. 2010. Research: towards socially attractive city squares. M.sc, Wageningen University and Research Centre.

SCHREIBER, J. B., NORA, A., STAGE, F. K., BARLOW, E. A. \& KING, J. 2006. Reporting Structural Equation Modeling and Confirmatory Factor Analysis Results: A review. The Journal of Educational Research, 99, 323-338.

SPOONER, D. 2014. Enhancing Campus Sustainability through sites and Socially Equitable Design. Planning for Higher Education Journal, 4, 30-45.

STEPHEN, C., RIVLIN, L. G., FRANCIS, M. \& STONE, A. M. 1992. Public Space, New York, Cambridge University Press. 
TABASSUM, S. \& SHARMIN, F. 2013. Accessibility Analysis of Parks at Urban Neighborhood: The Case of Dhaka. Asian Journal of Applied Science and Engineering, 2, 48-61.

TAGHIPOUR, M., SOLTANZADEH, H. \& AFKAN, K. B. 2015. The Role of Spatial Organization in Social Interaction of Residents of Residential Complexes (Case Study: Two Residential Complexes in Shiraz, Iran). Research Journal of Applied Sciences, Engineering and Technology, 10, 86-93.

THWAITES, K. 2005. Restorative Urban Open Space: exploring the spatial configuration of human emotional fulfillment in urban open space. Landscape research, 30, 525-547.

TIBBALDS, F. 1992. Making People Friendly Towns, Harlow : Longman.

TORABI, Z. \& BRAHMAN, S. 2013. Effective Factors in Shaping the Identity of Architecture. Middle-East Journal of Scientific Research, 15, 106-113.

WHYTE, W. H. 1980. The Social Life of Small Urban Spaces, New York, Project for Public Spaces.

ZAKARIYA, K., HARUN, N. Z. \& MANSOR, M. 2016. Space and Sociability: Mapping Melbourne's City Square. Asian Journal of Quality of Life, 1, 45-55. 